\title{
An infected mediastinal cyst
}

\author{
Lindsay M Lawson MD CM FRCPC ${ }^{1}$, Andrew C Mason MA MB BChir MRCP (UK) FRCR FRCPC 2 \\ ${ }^{1}$ Division of Respiratory Medicine, Department of Medicine and \\ ${ }^{2}$ Department of Radiology, St Paul's Hospital and The University of British Columbia, \\ Vancouver, British Columbia
}

\begin{abstract}
LM Lawson, AC Mason. An infected mediastinal cyst. Can Respir J 2000;7(2):191-192.

The authors describe a 43-year-old patient who had a mediastinal mass that became infected after a transbronchial needle aspirate biopsy. A paraspinal, extrapleural window with a saline-lidocaine mixture was created that allowed the placement of a percutaneous drainage catheter into the infected lesion. This procedure resulted in an excellent clinical outcome, and obviated the need for a thoracotomy and more invasive surgical management.
\end{abstract}

Key Words: Cyst; Mediastinum

\section{Kyste médiastinal infecté}

RÉSUMÉ : Les auteurs décrivent le cas d'un patient de 43 ans présentant un kyste médiastinal qui s'est infecté à la suite d'une biopsie d'aspiration transbronchique à l'aiguille fine. On a créé une fenêtre paraspinale extrapleurale avec un mélange de solution physiologique et de lidocaïne pour permettre l'installation d'un drain percutané. Cette intervention a donné lieu à d'excellents résultats cliniques et a permis d'éviter la thoracotomie et un traitement chirurgical plus vulérant.
A 43-year old male construction labourer had been previously well despite having smoked 1.5 packs of cigarettes daily for 20 years and having briefly smoked cocaine many years earlier. The patient had never used intravenous drugs. He was aware of some asbestos exposure.

Four months before hospital admission, the patient developed left-sided pleuritic chest pain. A chest x-ray taken at that time was normal, and he was treated with analgesics. One month later, he underwent another chest $\mathrm{x}$-ray because of persistant pain, and this film showed a subcarinal mass. A computed tomographic (CT) scan confirmed the presence of a $7 \times 4 \mathrm{~cm}$ subcarinal, mediastinal mass that was insinuating itself around, but not distorting, any of the surrounding structures. The mass was of uniform density ( 35 to 40 Hounsfield units) consistent with a benign process (eg, duplication foregut cyst or lymphocele). The patient was keen to confirm the presumed benign nature of this lesion and consequently underwent a fibreoptic bronchoscopy and transbronchial aspiration biopsy of the mass using a Wang needle (Milrose Laboratories, Mentor, Ohio). The bronchoscopical appearance was normal except for a widened carina; the procedure was uneventful and the needle aspirate specimen showed the cytological features of a benign cyst.

Thirteen days after the biopsy, the patient developed central chest pain, fever and chills. He was admitted to hospital, was found to be febrile and had a peripheral neutrophilia. A CT scan showed marked enlargement of the mediastinal mass with distortion of the left mainstem bronchus and deviation of the esophagus. To drain the cyst percutaneously, an extrapleural passage was created for a drainage catheter. Under CT control, the paravertebral extrapleural space was entered from the sixth intercostal space, $3.5 \mathrm{~cm}$ to the right of 


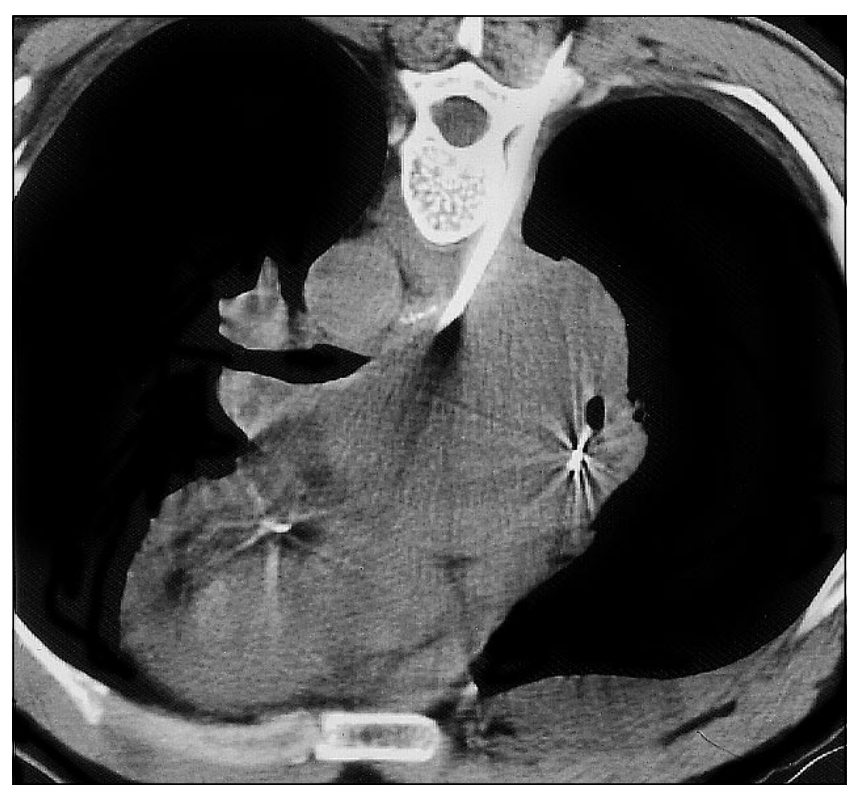

Figure 1) Computed tomographic scan image (with the patient prone) showing placement of the drainage catheter (the radiodense tubular structure adjacent to the vertebral body) through the paraspinal, extrapleural space into a large subcarinal mediastinal mass at the centre. The less radiodense material immediately surrounding the drainage catheter is the mixture of saline and lidocaine solution, and this mixture has accumulated within the pleura in a dependent manner on the anterior aspect of the chest

the midline. The right posterior paraspinal extrapleural space was infiltrated with a mixture of $100 \mathrm{~mL}$ of normal saline and $10 \mathrm{~mL}$ of $1 \%$ lidocaine, to create a small window to allow the extrapleural passage of a fine needle for aspiration of the infected cyst. A guidewire with a floppy distal segment was inserted through this needle into the cyst, and the track was sequentially dilated by use of the Seldinger technique to allow the passage of a 10 French pigtail catheter within the extrapleural space for indwelling drainage (Figure 1). Thick yellow fluid (the white blood cell count was $220,000 / \mathrm{mL}$ ) was drained that was culture-positive for betahemolytic streptococcus. The cyst was drained through the percutaneous catheter for using a Davol Reliavac 400 closed wound suction drain (CR Bond, Cranston, Rhode Island) 17 days with no lung or pleural complications (Figure 2), and the patient simultaneously received a three-week course of clindamycin. The patient made an excellent recovery, and CT scans repeated two and five months after discharge show the return of the cyst to its original size, with no interval change.

\section{DISCUSSION}

Cysts are unusual causes of mediastinal masses. In this patient, the CT density of the mass was suggestive of a simple cyst and an attempt was made to obtain a confirmatory cytological diagnosis. In retrospect, a percutaneous needle biopsy of the mass may have resulted in fewer complications, because fibreoptic bronchoscopy is not a sterile procedure

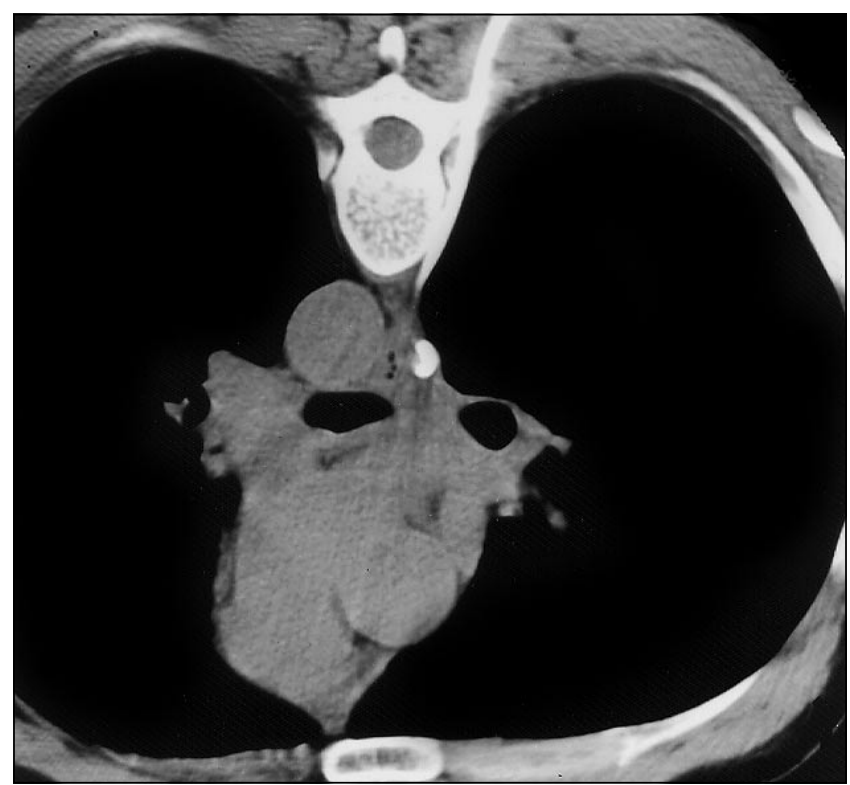

Figure 2) Computed tomographic scan image (with the patient prone) after drainage, showing marked reduction in the size of the subcarinal mass, with the catheter in good position

and bacteria may have been introduced into the cyst through the Wang needle. Percutaneous drainage techniques in the pleural space using CT or ultrasound guidance are well established (1). In cases of CT-guided biopsy of mediastinal masses or lymph nodes, recent papers have described widening of the extrapleural soft tissues with air, saline and lidocaine mixtures, or even with radiographic contrast media to create a safe window for access to the lesion (2-5). Artificial pneumothorax, created using a blunt needle to access the pleural space without damaging the lung has also been reported (6), but in our experience is more difficult to achieve consistently. In this particular case, there would have been a risk of contaminating the pleural space. Overall, the use of percutaneous drainage of an infected mediastinal cyst resulted in an excellent clinical outcome and avoided a thoracotomy.

\section{REFERENCES}

1. Klein JS, Schultz S, Heffner JE. Interventional radiology of the chest: Image-guided percutaneous draining of pleural effusions, lung abscess and pneumothorax. Am J Roentgenol 1995;164:582-8.

2. Langen H-J, Jochims M, Schneider W, Gunther RW. Distension of extrapleural spaces with contrast medium or air: Value in creating safe percutaneous access to the mediastinum in cadavers. Am J Roentgenol 1995;164:843-9.

3. Langen H-J, Klose KC, Keuler P, Adam G, Jochims M, Gunther RW. Artificial widening of the mediastinum to gain access for extrapleural biopsy: Clinical results. Radiology 1995;196:703-6.

4. Grant TH, Stull MA, Kandallu K, Chambliss JF. Percutaneous needle biopsy of mediastinal masses using a computed tomography-guided extrapleural approach. J Thorac Imaging 1998;13:14-9.

5. Bhagat VJ, Wilson MW, Sudilovsky D, LaBerge JM, Gordon RL, Kerlan RK. Percutaneous biopsy of a posterior mediastinal mass through an extrapleural window created with dilute contrast. J Thorac Imaging 1999;14:99-100.

6. Moore EH. Technical aspects of needle aspiration lung biopsy: A personal perspective. Radiology 1998;208:303-18. 


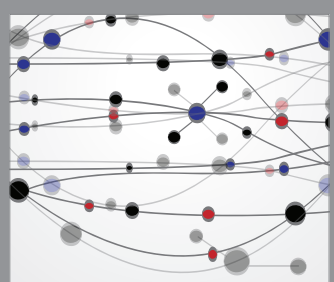

The Scientific World Journal
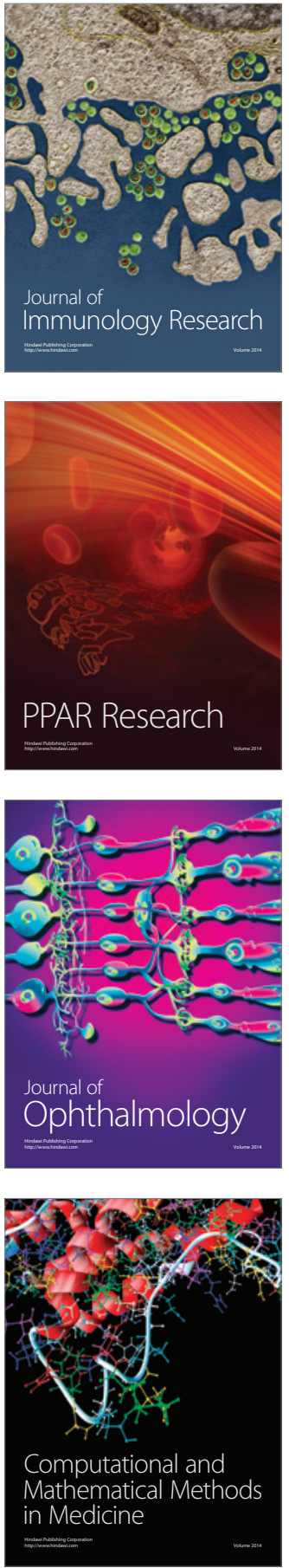

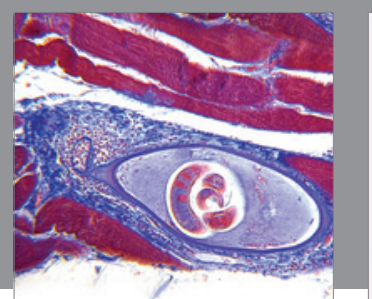

Gastroenterology Research and Practice

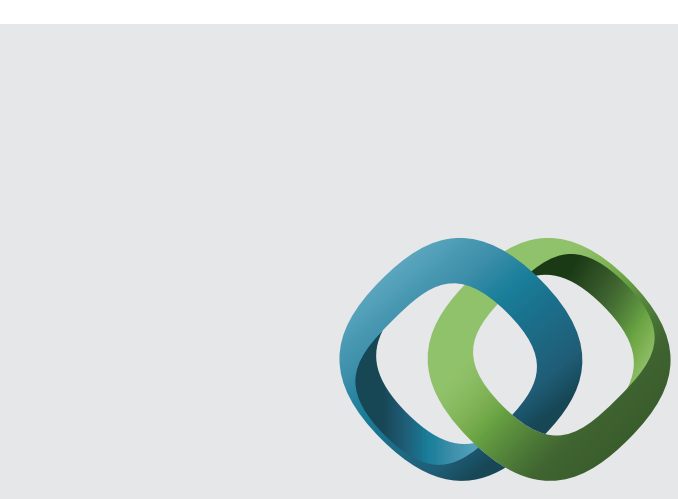

\section{Hindawi}

Submit your manuscripts at

http://www.hindawi.com
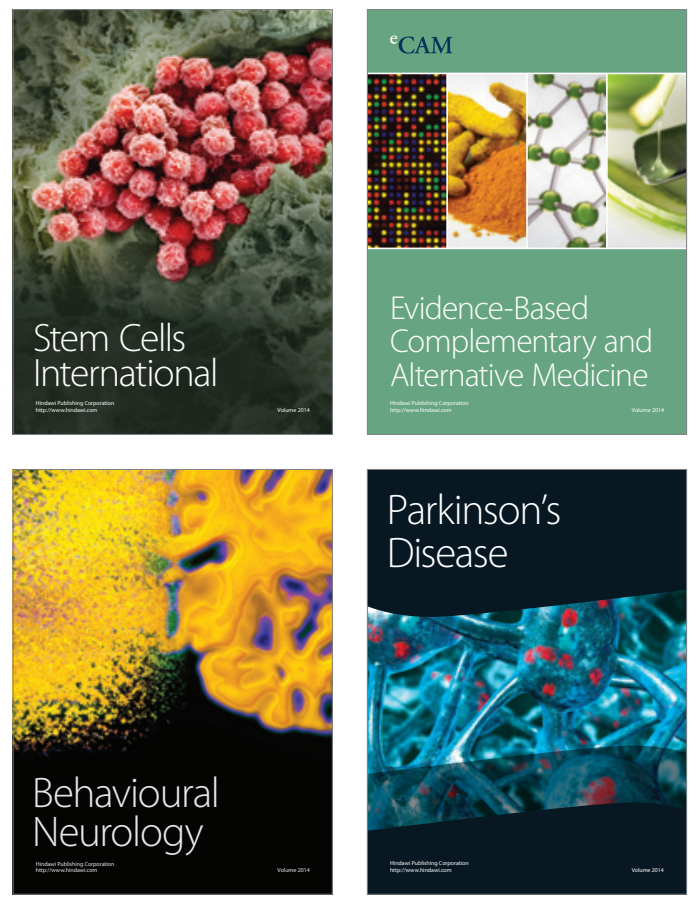
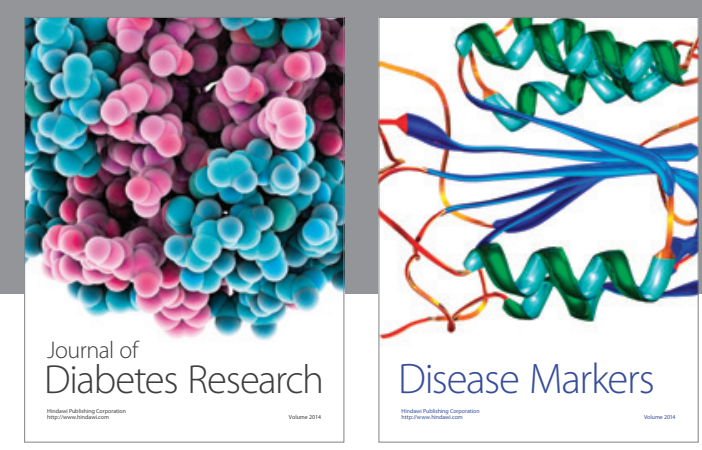

Disease Markers
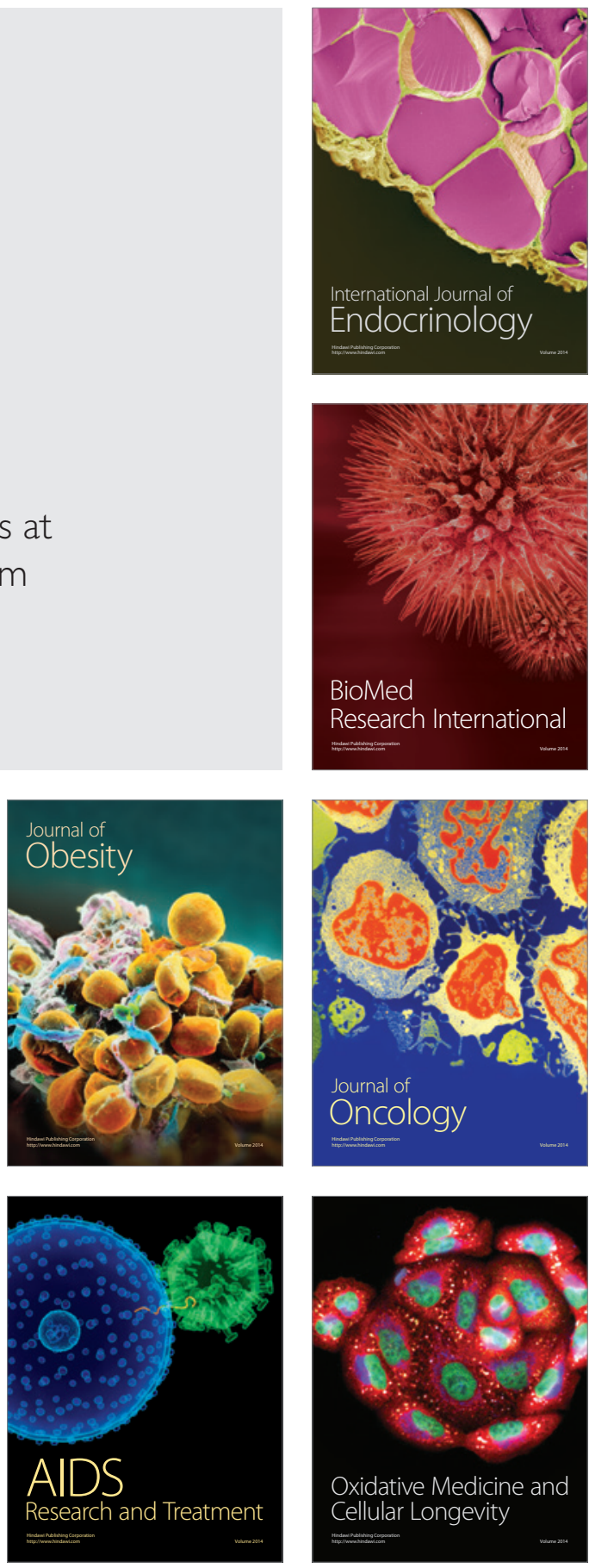